\title{
Structural Inequalities Established the Architecture for COVID-19 Pandemic Among Native Americans in Arizona: a Geographically Weighted Regression Perspective
}

\author{
Aggie J. Yellow Horse ${ }^{1}$ (D) Tse-Chuan Yang $^{2} \cdot$ Kimberly R. Huyser $^{3}$
}

Received: 1 June 2020 / Revised: 1 December 2020 / Accepted: 2 December 2020 / Published online: 19 January 2021

(C) W. Montague Cobb-NMA Health Institute 2021

\begin{abstract}
Native Americans are disproportionately affected by COVID-19. The present study explores whether areas with high percentages of Native American residents are experiencing the equal risks of contracting COVID-19 by examining how the relationships between structural inequalities and confirmed COVID-19 cases spatially vary across Arizona using a geographically weighted regression (GWR). GWR helps with the identification of areas with high confirmed COVID-19 cases in Arizona and with understanding of which predictors of social inequalities are associated with confirmed COVID-19 cases at specific locations. We find that structural inequality indicators and presence of Native Americans are significantly associated with higher confirmed COVID-19 cases; and the relationships between structural inequalities and confirmed COVID-19 cases are significantly stronger in areas with high concentration of Native Americans, particular on Tribal lands. The findings highlight the negative effects that lack of infrastructure (i.e., housing with plumbing, transportation, and accessible health communication) may have on individual and population health, and, in this case, associated with the increase of confirmed COVID-19 cases.
\end{abstract}

Keywords Native American · American Indian and Alaska Native Peoples · COVID-19 - Structural inequality $\cdot$ Concentrated disadvantage $\cdot$ Arizona $\cdot$ Indigenous data sovereignty

The coronavirus disease 2019 (COVID-19) pandemic has significantly impacted the United States with more than 1.3 million confirmed COVID-19 cases and over 84,000 related deaths as of mid-May 2020 [1]. Although the pandemic is ongoing and ever shifting in its nature, some preliminary data indicates that the pandemic has been disproportionately affecting racialized and minoritized populations [2-4]. For example, in New York, the lab-confirmed COVID-19 cases show

Aggie J. Yellow Horse

ajnoah@asu.edu

Tse-Chuan Yang

tyang3@albany.edu

Kimberly R. Huyser

kimberly.huyser@ubc.ca

1 School of Social Transformation, Arizona State University, Tempe, AZ, USA

2 Department of Sociology, The State University of New York at Albany, Albany, NY, USA

3 Department of Sociology, The University of British Columbia, Vancouver, BC, Canada that Black Americans have the largest proportion of confirm cases in absolute terms (32.6\% compared to $28.4 \%$ of nonHispanic/Latinx whites) even though non-Hispanic/Latinx Black population only accounts for $14.3 \%$ of the state's total population $[5,6]$. The age-adjusted rates show that Black Americans are more likely to be not hospitalized (335.5 per 1000 compared to 190.4 per 1000 for non-Hispanic/Latinx whites), and more likely to have died (92.3 per 1000 compared to 45.2 per 1000 for non-Hispanic/Latinx whites) [6]. Public health dialog on Black Americans during the current pandemic is important for not only documenting and understanding the different experiences and impacts of COVID-19 but also for "promoting and maintaining preventative measures" for Black Americans [4, 7, 8]. Similar substantial health inequities during the pandemic have been observed for Latinx population [9].

It is equally urgent and important to bring Native Americans ${ }^{1}$ into the center of the pandemic public health dialog. As descendants of the First Peoples of the America,

\footnotetext{
${ }^{1}$ We used the term "Native American" and "American Indians and Alaska Native Peoples" interchangeably. The use of "American Indian and Alaska Native Peoples" as plural is intentional to acknowledge multiple sovereign groups within the American Indians and Alaskan Native label.
} 
understanding Native American health and health emergencies related to COVID-19 has critical health and sociopolitical implications for not only Native Americans but also for the overall US population and Indigenous populations worldwide. Native American Peoples and communities are the "forgotten minority" often historically overlooked or excluded in health inequities research due to multiple theoretical and methodological complexities and challenges $[10,11]$. Key methodological challenges that contribute to invisibility of Native Americans in public health dialog are lack of Indigenous representation and race misclassification. Often due to small population size of Native Americans, most state- or national-level health statistics either omit Native Americans (lack of Indigenous representation via intentional exclusion) or misclassified Native Americans as "others" and even combined with other small groups (race misclassification). During the current pandemic, race misclassification is also substantially affecting how Native Americans are included or excluded in the US coronavirus data as Native Americans are often labeled as "other" and/or lumped with other small populations [12]. Such race misclassification is another form of systemic erasure of Native Americans in data, and it masks the health emergencies of Native Americans.

Parallel to Black American and Latinx experiences, Native Americans also have been disproportionately affected by COVID-19 [13]. Native Americans are highly diverse with 574 federally recognized Tribal Nations with unique histories, cultures, and languages. There are similar challenges across Native Nations originating from shared histories of genocide and systematic racism-including forced assimilation and separation of families through Indian boarding schools [14] and a series of federal laws establishing institutional marginalization [15]. Over time, these historical social injustices "get under the skin" [16] and translate to health inequities through multiple interconnected mechanisms including weathering (i.e., physiological manifestations of accumulative stress from historically embedded social inequalities) [17] and intergenerational transmissions [18, 19]. Consequently, Native Americans have the highest rates of obesity and diabetes [20], second highest rate of asthma (after Black Americans) ${ }^{2}$ [21], and the lowest rate of health insurance coverage than any other racial and ethnic groups [22]. Such health inequities prior to the current pandemic already puts Native Americans at a more vulnerable position given the current knowledge about the higher risks for severe illness from COVID-19 and death for individuals with underlying medical conditions including obesity, diabetes, and asthma [23]. That is, even if the equal risk of contracting COVID-19 is assumed, Native Americans are at higher risks for severe illness and death

\footnotetext{
${ }^{2}$ American Indian and Alaska Natives have the second highest rate of asthma compared to other racial groups, but higher endpoint of the confidence interval than Black population, and the rates are based on numbers of diagnosed cases.
}

due to pre-existing health inequities. Given these vulnerabilities among Native Americans, it is important to assess the risk of contracting COVID-19 among Native Americans relative to non-Native Americans.

\section{COVID-19 in Arizona Contexts and the Case of the Navajo Nation}

The present study focuses on Arizona, one of few states that released COVID-19 statistics with Native Americans as a racial category. Arizona has the largest concentration of singlerace American Indian and Alaska Native Peoples in the United States. Arizona's Native population accounts for nearly $11.4 \%$ $(309,580)$ of the total US American Indian and Alaska Native populations [5]. There are 22 federally recognized Tribal Nations in Arizona (Fig. 1) including Navajo $(149,115)$, Apache (29,055), Tohono O'odham (23,812), Pima $(20,035)$, Yaqui $(16,898)$, and Native Americans without Tribal affiliation (8395) and with two or more Tribal affiliations (6098) [5].

In Arizona, the Native Americans have been experiencing disproportionate impacts of COVID-19. Although Native Americans make up about $4.6 \%$ of the state's population, they comprise over $12 \%$ of the confirmed COVID-19 cases and $16 \%$ of COVID-19 related deaths as of May 2020 [25]. The Navajo Nation, the largest Tribal Nation in Arizona, has been one of the communities experiencing a great hit in particular. Since the first member of the Navajo Nation tested positive for Dik'os Ntsaaígíi-19 (COVID-19) on March 17, 2020, the numbers of confirmed COVID-19 cases and deaths began to increase at accelerated rates compared to the rest of the state and the country. As of May 18, 2020, the Navajo Nation has 4071 confirmed COVID-19 cases and over 100 deaths (see Fig. 2) [27]. As of early May, the Navajo Nation has the highest coronavirus cases per capital in the United States with roughly 1786 case per 100,000 (authors' own calculation based on most recent Navajo population census) even compared to two states with hardest hit by the COVID-19, New York (1751 cases per 100,000) and New Jersey (1560 cases per 100,000) $[1,26]$. This high number of cases on the Navajo Nation is paradoxical given what we know about the positive relationship between population density and infectious diseases [28] and rural nature of Navajoland [29].

While statistics clearly depict the health emergencies of the Navajo Nation on the reservation, this is only a partial picture of how Native Americans are experiencing COVID-19. About $53 \%$ of Navajo citizens reside outside of the Navajo Nation boundaries (i.e., $9 \%$ residing in border towns such as Gallup, $\mathrm{NM}$, and Winslow, $\mathrm{AZ}$ and $44 \%$ residing away from the reservation and border towns) [26] (see Fig. 1b). Native American experiences of COVID-19 outside of the reservation are not captured in statistics from the Navajo Nation 


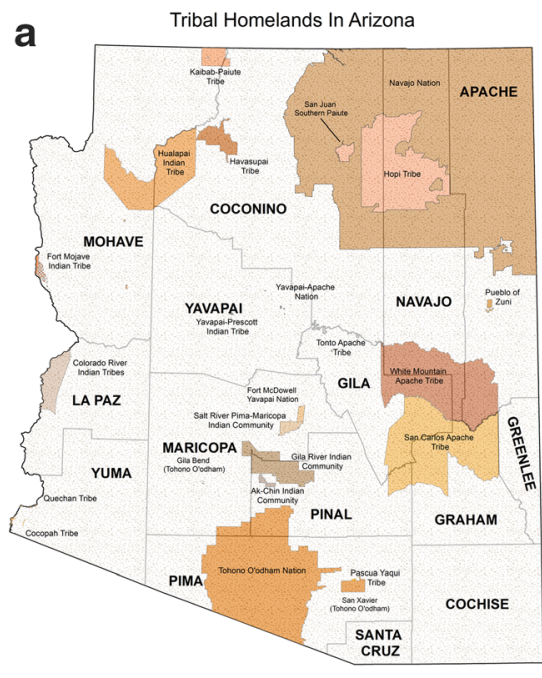

b

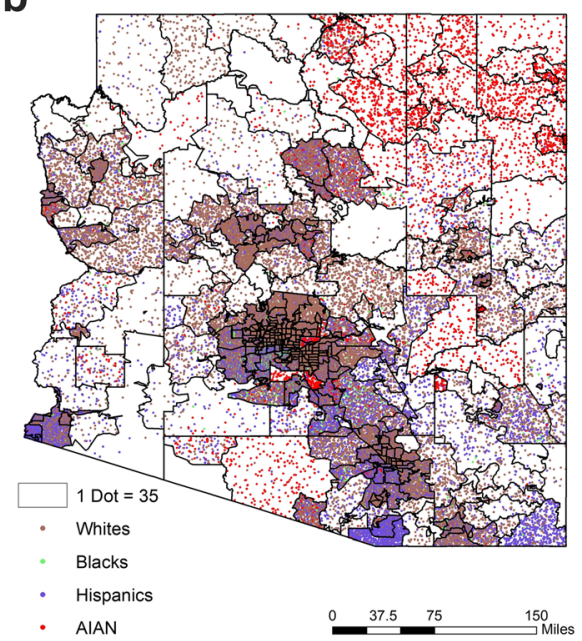

C

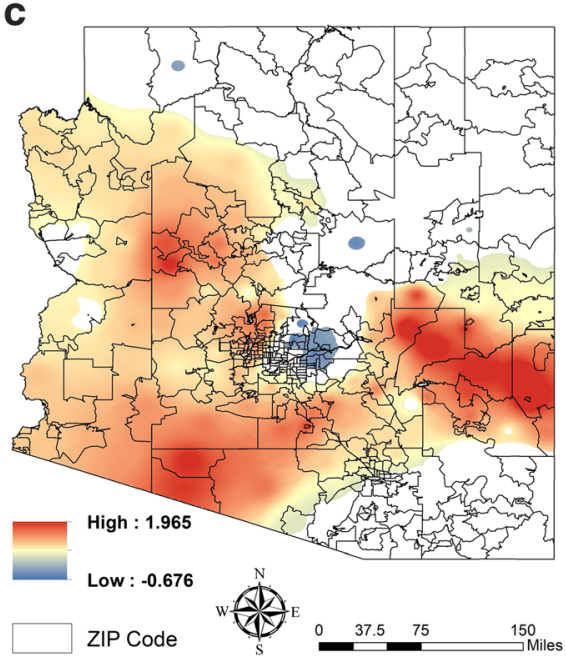

Fig. 1 Three maps of Arizona. a Tribal homelands in Arizona. b Dot densities of four racialized/minoritized groups by zip codes. $\mathbf{c}$ GWR results - impact of concentrated disadvantage on confirmed COVID-19 cases. Source: Fig. 1a, Inter Tribal Council of Arizona [24]. In c, we caution the interpretation for the Navajo Nation due to lack of information on Navajo Nation in our analyses because Tribal authorities are only gathering information about people on the Tribal lands. Furthermore, less or no information is available from other Tribal Nations in Arizona. In other words, the experiences of COVID-19 on the Navajo Nation are only a partial story of how COVID-19 is affecting Navajos and other Native Americans. Despite the critical need to understand and to center Native American experiences during the current pandemic, there has been limited empirical research to date that has exclusively focused on COVID-19 health emergencies among Native Americans [30].

\section{The Present Study}

Circumventing the poor data quality on Native Americans during COVID-19, the present study explores whether areas

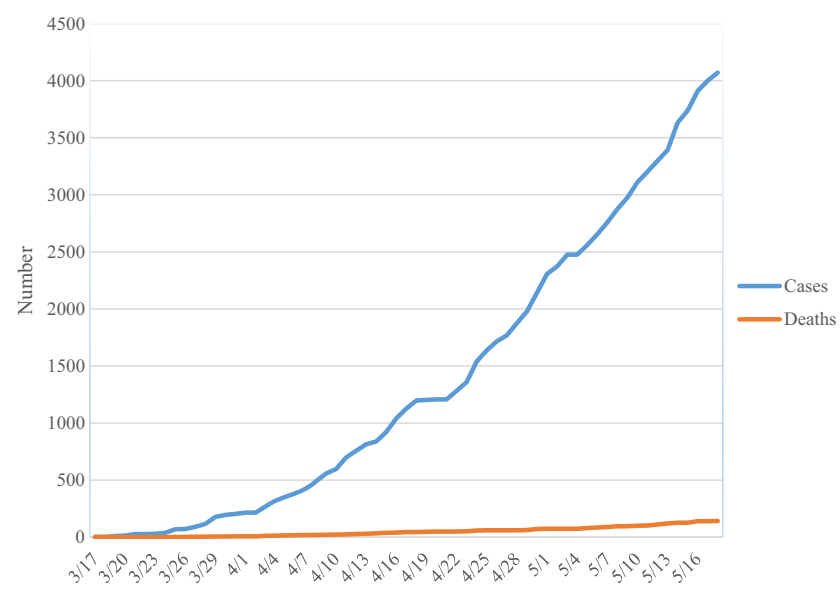

Fig. 2 Growth of the confirmed COVID-19 cases and deaths in Navajo Nation. Source: Navajo Division of Health [26] with high percentages of Native American residents are experiencing the equal risks of contracting COVID-19 by examining whether and how the relationships between structural inequalities and confirmed COVID-19 cases vary across Arizona. In this study, we are specifically interested in three interrelated questions: (1) what are the associations among the structural inequality measures and number of confirmed COVID-19 cases? (2) What is the association between the percent of Native Americans and the number of confirmed COVID-19 cases? (3) How do these associations vary spatially across Arizona?

To answer the third question, we used a geographically weighted regression (GWR). GWR is a spatial analytic method to resolve the problem of spatial autocorrelation in the residual and detect spatial non-stationarity. That is, GWR allows us to explore whether the relationship between a certain structural inequality measures and COVID-19 cases are statistically stable across space. For example, using GWR, scholars have reported that social association rates have both positive and negative relationships with mental health in the United States [31]. Without GWR, this localized dynamics cannot be unveiled. GWR can help with the identification of areas with high confirmed COVID-19 cases in Arizona and with understanding of which predictors of structural inequalities are associated with confirmed COVID-19 cases at specific locations. Although a standard multiple regression (Poison regression for count data) can identify the relationships between the predictors of structural inequalities and COVID19 confirmed cases, GWR can further identify whether these structural inequality factors associated with confirmed COVID-19 cases vary locally in Arizona. 


\section{Data and Methods}

We compiled the data from multiple courses for the zip codes in Arizona - as of May 14, 2020. We include all zip codes that correspond with United States Postal Service zip code service areas $(n=385)$. The dependent variable, the counts of confirmed COVID-19 cases, comes from the Arizona Department of Health Services [25]. The Arizona Department of Health Services released the count data by zip codes where over $90 \%$ of cases were mapped to the address of the patient's residence [25]. There were two important data issues. First, about $21.8 \%$ of zip codes had the confirmed COVID-19 case category than actual confirmed COVID-19 case count (for example, reporting " $1-5$ " instead of " 3 " cases). We took the total confirmed COVID-19 cases count at the county level, and then randomly assigned the numbers so that the total counts from zip codes in a specific county will add up to the total counts at the county level (i.e., residual method).

The second data issue was that $9.9 \%$ of zip codes $(n=38)$ were suppressed for areas where Native American residents make up more than $50 \%$ of the population [25]. We used the same residual method at the county level to estimate the total for the suppressed areas within a specific county, and then proportionated the cases by the population counts of zip codes for 38 zip codes where Native American residents account for more than half of the population. We based our residual method estimations on data from the Arizona Department of Health Services [25] and not from the Navajo Division of Health [26]. This decision was intentional to respect Indigenous data sovereignty of the Navajo Nation, the inherent authority of Tribal Nations to govern data about their peoples, lands, and resources [32]. Although the Arizona Department of Health Statistics data does not fully capture the cases on Navajo Nation and other Tribal lands, we decided not to use the numbers from the Navajo Nations for our estimation, as they have not publicly released their data by zip codes.

\section{Measures}

Drawing from the 2014-2018 American Community Survey (ACS) 5-year estimates, we include the several measures to capture structural inequalities (for question 1) and percentage of American Indian and Alaska Native persons (for question 2) at the zip code level. The first variable, concentrated disadvantage [33], is a composite score calculated with the principal component analysis (PCA) results. We constructed the concentrated disadvantage measure following previous studies investigating the role of neighborhood structural disadvantage on health inequities [34, 35]. Specifically, PCA was applied to the following six socioeconomic variables (factor loading in parentheses): percentage of population living below poverty $(0.872)$, percentage of female- headed households $(0.748)$, percentage of family receiving public assistance $(0.610)$, percentage of population aged 25 and older who did not have a high school diploma (0.829), percentage of unemployment for civilian population in labor force $(0.709)$, and logged median family income $(-0.836)$. The results indicated that one factor explains almost $60 \%$ of the variation among these variables, and the regression method was used to obtain the score, which represents the level of concentrated disadvantage in a zip code. Higher scores indicate higher concentrations of disadvantage. More detailed information about the exploratory factor analysis is available upon request. Regarding the percentage of American Indian and Alaska Native persons, it was calculated by dividing the number of population who selfidentified themselves as American Indian or Alaska Native person by total population who report at least one race/ethnicity in ACS.

COVID-19 is a contagious respiratory disease that is related to population density [36]. We calculated the population density by dividing the total population by the land area of a zip code (in square mile). In order to avoid numeric singularity when estimating our models, the population density is logarithm transformed in the analysis.

Adapting from the social vulnerability index, designed to identify areas that may be more socially vulnerable based on multiple indicators to be able to implement the place-based intervention and recovery from disaster [37] and used by previous study on the impacts of COVID-19 on Native American reservations [38]; we also considered several demographic and housing condition variables that are theoretically relevant to the pandemic of COVID-19, including percentage of population aged 65 and older, percentage of working population who did not have health insurance, percentage of housing units that have more than one person per room (i.e., overcrowding), percentage of housing units without complete kitchen facilities, and percentage of housing units without complete plumbing facilities. Moreover, percentage of working population who commute more than 60 min to work and the percentage of population who commute to work by public transportation are included in this study. Both variables are aimed at assessing the potential exposure to infection during commute.

The last two variables are language limitation and income inequality. The former is measured as the percentage of households that are limited in English speaking, whereas the latter is gauged with the Gini coefficient, ranging from 1 (completely unequal) to 0 (perfect equality). To more thoroughly address the concern about multicollinearity, we checked the variance inflation factor (VIF) and all VIFs are smaller than 5, suggesting that there were no issue of multicollinearity among the independent variables. 


\section{Methods}

As the dependent variable is the number of COVID-19 cases, we use both conventional Poisson regression and geographically weighted Poisson regression (GWPR) to estimate the relationships between the key independent variables and the mean of a Poisson distribution. We use logarithm as the link function. That is, a conventional Poisson regression model can be expressed as

$$
\begin{aligned}
& O_{i} \sim \text { Poisson }\left[E_{i} * \exp \left(\sum_{j} \beta_{j} *_{j, i}\right)\right] \\
& \log \left(O_{i}\right)=\log \left(E_{i}\right)+\beta_{0}+\sum_{j} \beta_{j}{ }^{*} x_{j, i}
\end{aligned}
$$

where $O_{i}$ represent the observed number of COVID-19 cases and $E_{i}$ is the total population-at-risk, which is treated as an offset variable and forced to have a regression coefficient of 1 . $\beta_{0}$ is the intercept and $\beta_{j}$ are the coefficients for the independent variables $j$ of zip code $i, x_{j, i}$.

The conventional Poisson regression model does not consider geographical locations and is unable to show the potential spatial varying associations between the key independent variables and the number of COVID-19 case. To address this issue, the GWPR was developed to examine the spatial varying coefficients over space and a GWPR model is expressed as

$$
\log \left(O_{i}\right)=\log \left(E_{i}\right)+\beta_{0, i}+\sum_{j} \beta_{j, i} * x_{j, i}
$$

The most notable difference with model (1) is that the regression coefficients $\left(\beta_{j, i}\right)$ are now specific to each zip code $i$ (i.e., spatial varying or location-specific coefficients). The GWPR allows geographically varying parameters and generates local spatial statistics. The best approach to summarizing the information generated by GWPR is to visualize and show the distributions of the local estimates [39].

The GWPR uses a kernel-based geographical weighting function to create spatial weights for each zip code. The principle of weighing is to place a kernel around a zip code and to compute the local coefficients $\left(\beta_{j, i}\right)$ using all the observations within the kernel window, which is determined by the bandwidth, $h$. The value $h$ that yields the smallest Akaike Information Criterion corrected (AICc) is selected as the most appropriate bandwidth in the kernel function. The estimation technique is based on iteratively reweighted least squares, with weights based on the bisquare kernel function:

$$
w_{i k}=\left[1-\left(\frac{d_{i k}}{h}\right)^{2}\right]^{2} \quad \text { if } d_{i k} \leq h, \text { otherwise } 0
$$

where $d_{i k}$ is the distance between the zip code $i$ and a nearby zip code $k$. According to the kernel function, zip codes closer to the zip code $i$ would carry more weight and have greater influence on parameter estimation than those farther away (if the distance between two zip codes is larger than $h$, the weight equals zero).

Two GWPR modeling issues should be noted. First, while various kernel functions are available, it has been suggested that the choice of kernel functions does not dramatically alter the geographically weighted regression results [40]. Second, this study uses adaptive bandwidth selection, which has been found to better fit unevenly distributed spatial data, such as when using the centroids of the US counties (which vary in geographical size) [40].

The coefficients in both global and local regression models can be interpreted exponentially as the sensitivity of the number of COVID-19 case to a change of one unit difference in the independent variable. The only difference in the coefficient interpretation between model (1) and (2) is that the GWPR coefficients can only be generalized to the number of COVID19 case within the zone covered by the kernel function and not to the whole state.

\section{Results}

Table 1 presents the descriptive statistics of the variables used in this study. We summarize the key findings as follows. On average, in a zip code, there are 33 COVID-19 cases and 18,325 residents. As the concentrated disadvantage is a factor score, it has a mean of 0 and standard deviation of 1 . Approximately $11 \%$ of population in a zip code is American Indian and Alaska Native persons, $21 \%$ of population are over 65 year old, and one out of six people $(16 \%)$ in working ages does not have health insurance.

In terms of housing conditions, almost $6 \%$ of housing units are overcrowded. Slightly more than $5 \%$ of housing units do not have complete kitchen facilities, in contrast to almost 3\% without complete plumbing facilities. Regarding commuting pattern, in an average zip code, almost $9 \%$ of working population spend more than 60 min on commute, but less than $2 \%$ of working population use public transportation as their means of commute. Finally, almost 5\% of households have limited English speaking ability and the average Gini coefficient is 0.427 , with a standard deviation of 0.069 . As shown in Table 2, concentrated disadvantage was strongly correlated with percentage of American Indian and Alaska Native persons and percentage of overcrowding housing units. Percentage of American Indian and Alaska Native persons was also strongly correlated with percentages of overcrowding housing units and households without complete plumbing. Though some correlations are moderate to strong, they do not directly translated into multicollinearity as confirmed by small VIFs.

The conventional Poisson regression results are summarized into Table 3. Model 1 only considers concentrated 
Table 1 Descriptive statistics

\begin{tabular}{lrrrc}
\hline & \multicolumn{1}{c}{ Mean } & S.D. & Min & Max \\
\hline Confirmed COVID-19 cases & 33.09 & 44.20 & 0.00 & 310 \\
Total population & $18,325.02$ & $18,498.85$ & 0.00 & 74,382 \\
Concentrated disadvantage & 0.00 & 1.00 & -1.71 & 4.56 \\
American Indian and Alaska native population & 11.25 & 26.89 & 0.00 & 100 \\
Logged population density & 4.70 & 3.00 & -3.00 & 9.29 \\
\% population over 65 & 21.40 & 14.81 & 0.00 & 84.42 \\
\% of adults without Insurance & 16.41 & 10.55 & 0.00 & 82.64 \\
\% overcrowded household & 5.69 & 8.29 & 0.00 & 100 \\
\% households without kitchen & 5.47 & 9.35 & 0.00 & 100 \\
\% households without plumbing & 2.90 & 9.27 & 0.00 & 100 \\
\% workers commuting more than 60 mins & 8.97 & 9.55 & 0.00 & 100 \\
\% workers commuting by public transportation & 1.55 & 2.97 & 0.00 & 25.93 \\
\% limited English speaking households & 4.77 & 7.28 & 0.00 & 49.30 \\
Gini coefficient & 0.43 & 0.07 & 0.05 & 0.72 \\
\hline
\end{tabular}

disadvantage, percentage of American Indian and Alaska Native persons, and logged population density. The results suggest that every one unit (i.e., standard deviation for this variable) increase in concentrated disadvantage is associated with $16 \%$ increase in the number of COVID-19 case $\left((\exp (0.1478)-1)^{*} 100 \%\right)$. Similarly, one percentage point increase in American Indian and Alaska Native persons is related to $3 \%$ increase in the number of COVID-19 infection $\left((\exp (0.0301)-1)^{*} 100 \%\right)$.

When adding older adults and percent of working population without health insurance into Model 2, the association between concentrated disadvantage and COVID-19 cases is reduced by $50 \%((0.0732-0.1478) / 0.1478)$. That is, every one unit increase in concentrated disadvantage is associated with almost $8 \%$ increase in COVID-19 cases ( $(\exp (0.0732)$ $1)^{*} 100 \%$ ). That said, these older adults and percent of working population without health insurance help to explain why structural inequality has a detrimental effect on COVID19 spread, and the increase in population without insurance is positively related to the number of COVID-19 case. It should be noted that the effect of American Indian and Alaska Native persons is almost unaltered in Model 2.

Model 3 further considers housing conditions and commuting pattern in a zip code. The effect of concentrated disadvantage is slightly reduced to $7 \%$ increase in COVID-19 infection, should we observe a one-unit increase in concentrated disadvantage. By contrast, the effect of American Indian and Alaska Native persons on COVID-19 seems to be suppressed by housing conditions and commuting pattern because the estimated coefficient increases from Model $2(\beta=0.033)$. In addition, as expected, housing units without complete plumbing facilities, working population who spend more than

Table 2 Correlation matrix of all included variables

\begin{tabular}{|c|c|c|c|c|c|c|c|c|c|c|c|c|}
\hline & {$[1]$} & {$[2]$} & {$[3]$} & {$[4]$} & {$[5]$} & {$[6]$} & {$[7]$} & {$[8]$} & [9] & {$[10]$} & {$[11]$} & {$[12]$} \\
\hline [1] Concentrated disadvantage & 1.000 & & & & & & & & & & & \\
\hline [2] AIAN population & 0.657 & 1.000 & & & & & & & & & & \\
\hline [3] Population density & -0.194 & -0.333 & 1.000 & & & & & & & & & \\
\hline [4] \% population over 65 & -0.372 & -0.246 & -0.302 & 1.000 & & & & & & & & \\
\hline [5] $\%$ of adults without insurance & 0.599 & 0.381 & -0.240 & -0.236 & 1.000 & & & & & & & \\
\hline [6] \% overcrowded household & 0.674 & 0.623 & -0.185 & -0.373 & 0.531 & 1.000 & & & & & & \\
\hline [7] \% households without kitchen & 0.509 & 0.705 & -0.435 & -0.058 & 0.283 & 0.474 & 1.000 & & & & & \\
\hline [8] \% households without plumbing & 0.498 & 0.673 & -0.331 & -0.101 & 0.369 & 0.687 & 0.761 & 1.000 & & & & \\
\hline [9] \% commuting more than 60 mins & 0.159 & 0.215 & -0.301 & 0.036 & 0.125 & 0.221 & 0.409 & 0.318 & 1.000 & & & \\
\hline [10] \% commuting by public transportation & 0.270 & 0.090 & 0.087 & -0.185 & 0.257 & 0.110 & -0.069 & 0.032 & 0.051 & 1.000 & & \\
\hline [11] \% limited English speaking households & 0.569 & 0.414 & -0.074 & -0.266 & 0.490 & 0.358 & 0.545 & 0.418 & 0.227 & 0.114 & 1.000 & \\
\hline [12] Gini coefficient & 0.302 & 0.351 & 0.042 & 0.032 & 0.136 & 0.162 & 0.212 & 0.108 & -0.079 & 0.041 & 0.137 & 1.000 \\
\hline
\end{tabular}


Table 3 Poisson regression model predicting the logged odds of confirmed COVID-19 cases in Arizona (global regression model) $N=385$

\begin{tabular}{|c|c|c|c|c|}
\hline & Model 1 & Model 2 & Model 3 & Model 4 \\
\hline Concentrated disadvantage & $\begin{array}{l}0.1478^{* * *} \\
(0.0117)\end{array}$ & $\begin{array}{l}0.0732^{* * *} \\
(0.0161)\end{array}$ & $\begin{array}{l}0.0682^{* * *} \\
(0.0188)\end{array}$ & $\begin{array}{l}0.0509^{*} \\
(0.0206)\end{array}$ \\
\hline American Indian and Alaska native population & $\begin{array}{l}0.0301^{* * * *} \\
(0.0005)\end{array}$ & $\begin{array}{l}0.0302^{* * * *} \\
(0.0005)\end{array}$ & $\begin{array}{l}0.0325^{* * *} \\
(0.0007)\end{array}$ & $\begin{array}{l}0.0331^{* * *} \\
(0.0007)\end{array}$ \\
\hline Population density & $\begin{array}{l}0.0834 * * * \\
(0.0060)\end{array}$ & $\begin{array}{l}0.0767 * * * \\
(0.0064)\end{array}$ & $\begin{array}{l}0.0712^{* * *} \\
(0.0068)\end{array}$ & $\begin{array}{l}0.0695 * * * \\
(0.0068)\end{array}$ \\
\hline$\%$ population over 65 & & $\begin{array}{l}0.0014 \\
(0.0010)\end{array}$ & $\begin{array}{l}0.0030^{* *} \\
(0.0010)\end{array}$ & $\begin{array}{l}0.0035^{* * *} \\
(0.0011)\end{array}$ \\
\hline$\%$ of adults without insurance & & $\begin{array}{l}0.0122^{* * *} \\
(0.0015)\end{array}$ & $\begin{array}{l}0.0110^{* * *} \\
(0.0015)\end{array}$ & $\begin{array}{l}0.0095^{* * *} \\
(0.0017)\end{array}$ \\
\hline$\%$ overcrowded household & & & $\begin{array}{l}0.0014 \\
(0.0027)\end{array}$ & $\begin{array}{l}0.0032 \\
(0.0029)\end{array}$ \\
\hline$\%$ households without kitchen & & & $\begin{array}{l}-0.0248^{* * *} \\
(0.0032)\end{array}$ & $\begin{array}{l}-0.0239^{* * *} \\
(0.0034)\end{array}$ \\
\hline$\%$ households without plumbing & & & $\begin{array}{l}0.0141^{\text {*** }} \\
(0.0037)\end{array}$ & $\begin{array}{l}0.0096^{*} \\
(0.0041)\end{array}$ \\
\hline$\%$ workers commuting more than 60 mins & & & $\begin{array}{l}0.0100^{* * *} \\
(0.0018)\end{array}$ & $\begin{array}{l}0.0088^{\text {*** }} \\
(0.0020)\end{array}$ \\
\hline$\%$ workers commuting by public transportation & & & $\begin{array}{l}0.0184^{* * *} \\
(0.0045)\end{array}$ & $\begin{array}{l}0.0194^{\text {**** }} \\
(0.0047)\end{array}$ \\
\hline \% limited English speaking households & & & & $\begin{array}{l}0.0050 * * \\
(0.0019)\end{array}$ \\
\hline Gini coefficient & & & & $\begin{array}{l}-0.1970 \\
(0.2329)\end{array}$ \\
\hline Intercept & $-7.1889^{* * *}$ & $-7.3575^{* * * *}$ & $-7.4091^{* * *}$ & $-7.3272^{* * *}$ \\
\hline Pseudo R-sq & 0.6030 & 0.6076 & 0.6149 & 0.6154 \\
\hline AIC & 5907.7924 & 5843.9025 & 5745.1525 & 5741.4960 \\
\hline
\end{tabular}

Note: ${ }^{*} p<0.05 ;{ }^{* *} p<0.01 ;{ }^{* * *} p<0.001$
60 min on commute, and working population who use public transportation all demonstrate a positive association with COVID-19 infection.

In Model 4, Gini coefficient and language limitation seem to explain why concentrated disadvantage aggravates COVID-19 infection. Specifically, when including these two variables, the effect of concentrated disadvantage further drops by more than $25 \%$ ((0.0509-0.0682)/0.0682). As such, a one-unit increase in concentrated disadvantage is only associated with $5 \%$ increase in COVID-19 cases ( $(\exp (0.0509)$ 1) $100 \%$ ). In contrast to Model 1 , our independent variables, overall, explain two-thirds of the effect. We would like to emphasize that zip codes hosting more households with limited English speaking ability tend to have more confirmed COVID-19 cases.

Based on Model 4, we implement GWPR analysis and summarize the GWPR results into Table 4 and Fig. 1c as the literature suggests [40]. The five-number summary provides an overview of how the local coefficients vary across study area, and we conduct the test for spatial variability with the Chi- square test in selection criterion for each independent variable. The spatial variability test results are shown in the last column of Table 4 and a negative value suggests that the spatial variability is significant in a certain variable [41]. As all the values in the last column are negative, we have evidence to conclude that the associations between all covariates and COVID-19 cases vary significantly across zip codes. We visualize the coefficient of concentrated disadvantage in Fig. 1c. In comparison to the map of Tribal homelands in Arizona on the left side of Fig. 1, the Fig. 1c map shows that the areas that have the strong associations among structural inequality factors and COVID-19 cases were especially high on Tribal Nations - namely, Tohono O'odham Nation, White Mountain Apache Reservation, and San Carlos Apache Indian Reservation.

\section{Conclusion}

Native American Peoples and communities are disproportionately affected by the COVID-19 pandemic [13]. There is an 
Table 4 Geographically weighted regression summary results

\begin{tabular}{|c|c|c|c|c|c|c|c|}
\hline & Min & Q1 & Q2 & Q3 & Max & $\begin{array}{l}\text { Diff- } \\
\text { criterion+ }\end{array}$ & Spatial Variation \\
\hline Intercept & -11.59 & -7.96 & -7.37 & -6.46 & -0.08 & -34.10 & Non-stationary $^{* * *}$ \\
\hline Concentrated disadvantage & -0.68 & 0.02 & 0.35 & 0.64 & 1.97 & -65.74 & Non-stationary ${ }^{* * *}$ \\
\hline American Indian and Alaska native population & -0.14 & 0.00 & 0.03 & 0.05 & 0.13 & -62.17 & Non-stationary ${ }^{* * *}$ \\
\hline Logged population density & -0.22 & -0.04 & 0.01 & 0.09 & 0.38 & -222.88 & Non-stationary ${ }^{* * *}$ \\
\hline$\%$ population over 65 & -0.04 & -0.01 & 0.00 & 0.02 & 0.07 & -61.84 & Non-stationary ${ }^{* * *}$ \\
\hline$\%$ of adults without insurance & -0.12 & -0.03 & -0.01 & 0.01 & 0.08 & -27.74 & Non-stationary $^{* * *}$ \\
\hline$\%$ overcrowded household & -0.14 & -0.03 & 0.00 & 0.07 & 0.21 & -96.81 & Non-stationary ${ }^{* * *}$ \\
\hline$\%$ households without kitchen & -0.38 & -0.11 & -0.01 & 0.06 & 0.29 & -33.85 & Non-stationary ${ }^{* * *}$ \\
\hline$\%$ households without plumbing & -1.17 & -0.42 & -0.09 & 0.02 & 0.51 & -88.74 & Non-stationary $^{* * * *}$ \\
\hline$\%$ workers commuting more than $60 \mathrm{mins}$ & -0.10 & -0.02 & 0.00 & 0.02 & 0.06 & -5.53 & Non-stationary $^{* * *}$ \\
\hline$\%$ workers commuting by public transportation & -0.31 & -0.04 & 0.04 & 0.09 & 0.91 & -118.40 & Non-stationary ${ }^{* * *}$ \\
\hline$\%$ limited English speaking households & -0.16 & -0.06 & -0.01 & 0.01 & 0.24 & -13.89 & Non-stationary $^{* * *}$ \\
\hline Gini coefficient & -20.41 & -1.00 & 1.64 & 3.21 & 15.14 & -307.50 & Non-stationary ${ }^{* * *}$ \\
\hline
\end{tabular}

Note: Diff-criterion refers to the Chi-square test result in the difference between the original GWR model and the constant model ${ }^{*} p \leq 0.05 ;{ }^{* *} p \leq 0.01 ;{ }^{* * *} p \leq 0.001$

immutable need to understand Native experiences beyond the current statistics and contextualize Indigenous health inequities with sociohistorical and political structural indicators that contribute to enduring health inequities. Aligned with such goal, the present study investigated the relationships between structural inequalities and the confirmed COVID-19 cases in Arizona and spatial variations of the relationships as of mid-May 2020. The results indicate that structural inequalities prior to the current pandemic are strongly associated with high cases of confirmed COVID-19 cases in Arizona. At the baseline, concentrated disadvantage and presence of Native Americans are both significantly and positively associated with higher number of confirmed COVID-19 cases. These associations do not disappear when we control for other demographic and housing conditions. The relationship between Native Americans and COVID-19 is partially explained by housing conditions such as housing units without complete plumbing facilities, which is consistent from findings from other reservations [38]. This indicates that poor housing conditions are key factors in why Native Americans have disproportionally higher numbers of confirmed COVID19 cases in Arizona. Lastly, we found that areas with more households with limited English speaking ability tend to have more confirmed COVID-19 cases. This demonstrates the importance of translating COVID-19 related health messages (e.g., written and audible communication) in non-English languages including multiple Indigenous languages beyond Spanish and Asian languages. For example, on Navajoland (i.e., Navajo Reservation), only $9.3 \%$ of households speak English only and $89.4 \%$ of households speak Indigenous languages (and 19.6\% of limited English speaking households) [42]. ${ }^{3}$ The effects of housing conditions and language are similar to other research on COVID19 prevalence on Native American reservations [38].

Furthermore, the relationship between structural inequalities and confirmed COVID-19 cases are especially strong in the areas with high concentration of Native Americans. This pattern is so stark that the map of GWR results displaying the spatial relationship between concentrated disadvantage and confirmed COVID-19 cases are almost identical with the map of Tribal lands in Arizona (with the exception of the Navajo Nation due to data restriction). GWR results demonstrate that the relationships between structural inequality factors and COVID-19 cases were especially high on Tribal Nations-namely, Tohono O'odham Nation, White Mountain Apache Reservation, and San Carlos Apache Indian Reservation. That is, these Tribal Nations were the "hot spots" in Arizona. The results also suggest that reservations lands themselves epitomize the existence of structural inequality that facilitated the COVID-19 pandemic. This finding is critical for any public health mitigation efforts for combating COVID-19 because it highlights that such efforts need to simultaneously focus on proximal factors (e.g., providing enough personal protective equipment and access to testing) as well as distal factors (e.g., improving housing conditions and access to water). Furthermore, federal and state agencies must commit to providing greater institutional and

\footnotetext{
${ }_{3}^{3}$ Indigenous languages are assumed for what ACS labels as "Other Languages". Other languages do not include English, Spanish, other IndoEuropean languages, and Asian and Pacific Island languages.
} 
instrumental support to Tribal Nations. This support will build respect for Tribal sovereignty and will facilitate data informed decisions to address the specific needs of their own Tribal communities [38, 43].

The primary implications of our results are that structural inequalities and presence of Native American residents are significantly associated with the high numbers of confirmed COVID-19 cases in Arizona. Tribal Nations experienced greater effects of structural inequalities. These findings suggest that Native Americans are disproportionately affected by the current pandemic through multiple mechanisms, not only are they at higher risk for severe illness and death if they contract the COVID-19 at the individual level, they also reside in areas with higher concentration of confirmed COVID-19 cases, especially those residing on Tribal lands [44]. This can suggest that Native Americans face the higher risk of exposure in their own communities. This is largely consistent with the COVID-19 statistics in Arizona at large as Native Americans account for over $12 \%$ of the confirmed cases and $16 \%$ of COVID-19 related deaths even though they make up for only about $4.6 \%$ of the state's population [25].

Similar to Black American and Latinx experiences, Native Americans are experiencing substantial health inequities due to the residual effects of systematic racism in the form of health injustices during the current pandemic. ${ }^{4}$ Although the current pandemic is affecting everyone, the impacts of COVID-19 are more profound, deleterious, and multifaceted for Native Americans based on their race, Tribal affiliation, class, gender, age, language, and places of residence. For example, although data is currently unavailable, we suspect that the residents of Navajo Nation are differently affected by the current pandemic than non-Native Americans as well as Native Americans residing outside of the Navajo Nation boundaries. Those who reside in areas with limited access to water [45] — as the results of abandoned uranium mines and contamination of water from environmental racism [46]may have higher probability of contracting COVID-19 due to their lessened ability to wash their hands frequently. Furthermore, racism and stigma also contribute to health emergencies for Native Americans [47, 48]. For example, a white male of Page, the border town of the Navajo Nation, was arrested in April when he publicly posted on social media to kill all Navajos because they were " $100 \%$ infected" with COVID-19 [49]. Also, non-Native tourists and travelers have not fully complied with the closure of Tribal lands, thus, likely further increasing exposure to Tribal community members.

In the midst of combating the health emergencies spilling over from the lasting effects of structural inequalities for Native Americans, there are incredible ongoing efforts at

\footnotetext{
4 The residual effects of systemic racism do not insinuate that there is an ongoing systemic racism currently; but highlights that the effects of racism are long lasting and multi-dimensional.
}

multiple levels from the Native American Peoples, communities, and Tribal leadership to protect Native Peoples and promote individual and collective resiliency. In April 2020, the Navajo Nation and 10 other Tribal Nations have successfully fought and won a lawsuit against the US Secretary of the Treasury to ensure the equitable and just distribution of the Coronavirus Relief Fund to help Tribal governments and not profit the shareholders of the for-profit corporations [50]. The Navajo Nation President Jonathan Nez has been proactive in instituting policy in place (e.g., curfew orders) and high numbers of testing. He has been involved in on the ground efforts to help the citizens of Navajo Nation through distributing food, masks, and other essential items to elders and other community members. Community organizations like NATIVE HEALTH of Phoenix have expanded their services to distribute food for children and families during this time while staying committed to their core missions of empowering communities through addressing the social determinants of health through combating housing insecurity and providing employment services as well as cultural and educational programs. In addition, considerable efforts have been made to make the information available in Indigenous languages throughout the pandemic, as many Native American elders are fluent in Indigenous languages only. Most importantly, Native American Peoples have been actively supporting each other in the community-e.g., organizing donation drives then delivering essential items to the elders on reservation lands and to Native American families in urban areas whose members have contracted the coronavirus.

There are a few limitations of this study. Due to limitations in data availability, the complete counts of confirmed COVID-19 cases for the zip codes in Navajo Nation are not fully captured. There is a great need for the state's effort to capture the racial inequities of the pandemic with greater accuracy and reliability, especially for those reside on the Tribal lands. Indeed, it is critical to respect the Tribal Nations' Indigenous data sovereignty to make decisions about information pertaining to their peoples, lands, and resources [32] and not make overreaching investigations without Tribal authorities and peoples. A second limitation is the cross-sectional nature of this study as it captures the associations between structural inequalities and the confirmed COVID-19 cases based on data from May 14, 2020. As the pandemic is ongoing and ever shifting in nature, future research should explicitly consider the temporal component in addition to the consideration of the spatial component. Third, the current study only focuses on Arizona. Experiences of Native Americans from other states likely qualitatively and substantially differ. Lastly, the interpretation should use cautions as the confirmed COVID-19 cases do not reflect the current risk of transmission as the numbers represent the accumulated total over a few months. 
Despite these limitations, the study brings Native American experiences during the current pandemic to the center of the public health dialog. It illuminates the strong relationships between structural inequalities and confirmed COVID-19 cases and how they vary across Arizona. The findings also highlight the enduring structural inequality artifact that is reservation lands and how this particular structural factor influences the disproportionate impacts of the pandemic. The study urges public health researchers to critically integrate the multidimensionality of historical social injustices on Native Americans into the social determinants of the health framework. In other words, it is not enough to reduce the disproportionate impacts of the current pandemic for Native Americans, but there needs to be a systematic, holistic, culturally relevant, and Tribal-driven commitment to address the social determinant of health among Indigenous Peoples both on Tribal lands and in urban areas.

\section{Compliance with Ethnical Standards}

Conflict of Interest The authors declare that there is no conflict of interests.

Ethical Approval This article does not contain any studies with human participants performed by any of the authors.

\section{References}

1. Centers for Disease Control and Prevention. Coronavirus disease 2019 (COVID-19) cases, data \& surveillance: cases in the United States. 2020. https://www.cdc.gov/coronavirus/2019-ncov/casesupdates/cases-in-us.html. Accessed 1 June 2020.

2. Centers for Disease Control and Prevention. COVID-19 in racial and ethnic minority groups. 2020. https://www.cdc.gov/ coronavirus/2019-ncov/need-extra-precautions/racial-ethnicminorities.html. Accessed 1 June 2020.

3. Chowkwanyun M, Reed AL Jr. Racial health disparities and Covid19-caution and context. N Engl J Med. 2020;383:201-3.

4. Webb Hooper M, Nápoles AM, Pérez-Stable EJ. COVID-19 and racial/ethnic disparities. JAMA. 2020;323(24):2466-7.

5. U.S. Census Bureau. 2014-2018 American community survey 5year estimate. Washington, DC: U.S. Census Bureau. 2020.

6. City of New York. Age-adjusted rates of lab confirmed COVID-19 non hospitalized cases, estimated non-fatal hospitalized cases, and patients known to have died 100,000 by race/ethnicity group as of April 16, 2020. 2020. https://www1.nyc.gov/assets/doh/ downloads/pdf/imm/covid-19-deaths-race-ethnicity-04162020-1. pdf. Accessed 1 June 2020.

7. Laurencin CT, McClinton A. The COVID-19 pandemic: a call to action to identify and address racial and ethnic disparities. J Racial Ethn Health Disparities. 2020;7:398-402.

8. Braithwaite R, Warren R. The African American petri dish. J Health Care Poor Underserved. 2020;31:491-502.

9. Macias Gil R, Marcelin JR, Zuniga-Blanco B, Marquez C, Mathew T, Piggott DA. COVID-19 pandemic: disparate health impact on the Hispanic/Latinx population in the United States. J Infect Dis. 2020;222(10):1592-5.
10. Crump AD, Etz K, Arroyo JA, Hemberger N, Srinivasan S. Accelerating and strengthening Native American health research through a collaborative NIH initiative. Prev Sci. 2020;21(1):1-4.

11. Jim MA, Arias E, Seneca DS, Hoopes MJ, Jim CC, Johnson NJ, et al. Racial misclassification of American Indians and Alaska natives by Indian Health Service contract health service delivery area. Am J Public Health. 2014;104(S3):S295-302.

12. Yellow Horse AJ, Huyser KR. Indigenous data sovereignty and COVID-19 data issues for American Indian and Alaska Native Tribes and populations. J Popul Res, under review.

13. Hatcher SM, Agnew-Brune C, Anderson M, Zambrano LD, Rose CE, Jim MA, et al. COVID-19 among American Indian and Alaska Native persons - 23 states, January 31-July 3, 2020. Morb Mortal Wkly Rep. 2020;69(34):1166-9.

14. Lomawaima KT. They called it prairie light: the story of Chilocco Indian school. Lincoln, NE: Univ of Nebraska Press. 1995.

15. Wilkins DE, Lomawaima KT. Uneven ground: American Indian sovereignty and federal law. Norman, OK: Univ of Oklahoma Press. 2001.

16. Taylor SE, Repetti RL, Seeman T. Health psychology: what is an unhealthy environment and how does it get under the skin? Annu Rev Psychol. 1997;48(1):411-47.

17. Geronimus AT. The weathering hypothesis and the health of African-American women and infants: evidence and speculations. Ethnicity \& disease. 1992;2(3):207-21.

18. Brave Heart MYH. The historical trauma response among natives and its relationship with substance abuse: a Lakota illustration. J Psychoactive Drugs. 2003;35(1):7-13.

19. Palacios JF, Portillo CJ. Understanding native women's health: historical legacies. J Transcult Nurs. 2009;20(1):15-27.

20. Centers for Disease Control and Prevention. Summary health statistics: National Health Interview Survey 2018. Washington DC: Centers for Disease Control and Prevention. 2020.

21. Akinbami LJ, Moorman JE, Bailey C, et al. Trends in asthma prevalence, health care use, and mortality in the United States, 20012010. NCHS data brief, no 94. Hyattsville, MD: National Center for Health Statistics. 2012.

22. DeNavas-Walt C, Proctor BD, Smith JC. Income, poverty, and health insurance coverage in the United States: 2012. Current Population Reports P60-245. Washington, DC: U.S. Census Bureau. 2013.

23. Centers for Disease Control and Prevention. Information for healthcare professionals: COVID-19 and underlying conditions. 2020. https://www.cdc.gov/coronavirus/2019-ncov/hcp/ underlying-conditions.html. Accessed 1 June 2020.

24. Inter Tribal Council of Arizona. Tribal homelands in Arizona. 2020. https://itcaonline.com/maps/. Accessed 1 June 2020.

25. Arizona Department of Health Services. Coronavirus diseases 2019 (COVID-19) data dashboard. 2020. https://azdhs.gov/ preparedness/epidemiology-disease-control/infectious-diseaseepidemiology/covid-19/dashboards/index.php. Accessed 1 June 2020.

26. Navajo Division of Health. Navajo population profile, 2010 U.S. Census. Window Rock, AZ: Navajo Division of Health. 2013.

27. The Navajo Nation. May 10, 2020: 149 new cases of COVID-19 and two more deaths reported. Window Rock, AZ: Office of the President and Vice President of the Navajo Nation. 2020.

28. $\mathrm{Hu} \mathrm{H}$, Nigmatulina $\mathrm{K}$, Eckhoff $\mathrm{P}$. The scaling of contact rates with population density for the infectious disease models. Math Biosci. 2013;244(2):125-34.

29. Kovich H. Rural matters - coronavirus and the Navajo nation. N Engl J Med. 2020;383:105-7.

30. Akee R. Identifying differences in COVID-19 rates in American Indian reservations. 2020. J Public Health Manag Pract Direct Blog. https://jphmpdirect.com/2020/04/28/identifying-differences-in- 
covid-19-rates-on-american-indian-reservations/. Accessed 1 Jun 2020.

31. Ha H. Using geographically weighted regression for social inequality analysis: association between mentally unhealthy days (MUDs) and socioeconomic status (SES) in US counties. Int J Environ Health Res. 2019;29(2):140-53.

32. Kukutai T, Taylor J. Indigenous data sovereignty: toward an agenda. New York, NY: Anu Press. 2016.

33. Sampson RJ, Raudenbush SW, Earls F. Neighborhoods and violent crime: a multilevel study of collective efficacy. Science. 1997;277(5328):918-24.

34. Browning CR, Cagney KA. Neighborhood structural disadvantage, collective efficacy, and self-rated physical health in an urban setting. J Health Soc Behav. 2002;43(4):383-99.

35. Carpiano RM, Lloyd JE, Hertzman C. Concentrated affluence, concentrated disadvantage, and children's readiness for school: a population-based, multi-level investigation. Soc Sci Med. 2009;69(3): 420-32.

36. Yamada T, Dautry A, Walport M. Ready for avian flu? Nature. 2008;454(7201):162.

37. Flanagan BE, Gregory EW, Hallisey EJ, et al. A social vulnerability index for disaster management. J Homel Secur Emerg Manag. 2011;8(1):1-24.

38. Rodriguez-Lonebear D, Barceló NE, Akee R, Carroll SR. American Indian reservations and COVID-19: correlates of early infection rates in the pandemic. J Public Health Manag Pract. 2020;26(4):371-7.

39. Fotheringham AS, Brunsdon C, Charlton M. Geographically weighted regression: the analysis of spatially varying relationships. New York, NY: John Wiley \& Sons. 2003.

40. Fotheringham AS, Brunsdon C, Charlton M. Scale issues and geographically weighted regression. In: Modelling scale in geographical information science. Tate N, Atkinson PM, editors. Chichester, UK: John Wiley \& Sons; 2001. pp. 123-140.

41. Nakaya T, Fotheringham AS, Charlton $M$ et al., Semiparametric geographically weighted generalised linear modelling in GWR
4.0. 2009. http://mural.maynoothuniversity.ie/4846/1/MC_ Semiparametric.pdf. Accessed 1 June 2020.

42. U.S. Census Bureau. 2014-2018 American community survey 5year estimate. Washington, DC: U.S. Census Bureau. 2020.

43. Hoss A, Tanana H. Upholding tribal sovereignty and promoting tribal public health capacity during the Covid-19. In: Assessing legal responses to Covid-19. Burris S, de Guia S, Gable L. et al., editors. Boston, MA: Public Health Law Watch; 2020. pp. 1-34.

44. Williams DR, Collins C. Racial residential segregation: a fundamental cause of racial disparities in health. Public Health Rep. 2016;116(1):404-16.

45. Deitz S, Meehan K. Plumbing poverty: mapping hot spots of racial and geographic inequality in US household water insecurity. Ann Am Assoc Geogr. 2019;109(4):1092-109.

46. Deschine Parkhurst NA, Huyser KR, Yellow Horse AJ. Historical environmental racism, structural inequalities, and Dik'os Ntsaaígíí19 (COVID-19) on Navajo Nation. J Indigenous Soc Dev. 2020;9(3):127-140.

47. Hatzenbuehler ML, Phelan JC, Link BG. Stigma as a fundamental cause of population health inequalities. Am J Public Health. 2013;103(5):813-21.

48. Phelan JC, Link BG. Is racism a fundamental cause of inequalities in health? Annu Rev Sociol. 2015;41:311-30.

49. Fox News. Page man arrested for urging killings of Navajo over coronavirus. 2020. https://www.fox10phoenix.com/news/pageman-arrested-for-urging-killings-of-navajo-over-coronavirus. Accessed 1 June 2020.

50. Powell K. Court rules in favor of Navajo Nation lawsuit for Coronavirus Relief Fund. 2020. https://www.azfamily.com/news/ continuing_coverage/coronavirus_coverage/court-rules-in-favorof-navajo-nation-lawsuit-for-coronavirus-relief-fund/article 7be46fe6-8901-11ea-8466-93bb8a0c911b.html. Accessed $\overline{1}$ June 2020.

Publisher's Note Springer Nature remains neutral with regard to jurisdictional claims in published maps and institutional affiliations. 